\title{
Os determinantes da migração no Brasil: uma análise Probit para os anos de 2004, 2009 e 2014
}

\section{Determinants of migration in Brazil: a Probit analysis for the years 2004, 2009, and 2014}

\author{
Fransuellen Paulino-Santos* \\ Anna Clara Vieira-Silva* \\ Francisco Carlos Da Cunha-Cassuce* \\ Jader Fernandes-Cirino*
}

\begin{abstract}
This paper analyzes the interstate migratory process focusing on the more educated individuals, besides other characteristics that affect the decision to migrate. Data from the years 2004, 2009, and 2014 were extracted from the microdata of the National Survey by Household Sample (PNAD) for the 26 units of the federation and the Federal District. The probit model is used to calculate the probabilities and the results are analyzed based on the construction of scenarios. After the investigation, it is concluded that, for the investigated years in Brazil, the higher the education of the individual, the greater the probability of migrating.
\end{abstract}

Keywords: migratory process, probit, schooling.

\section{Resumo}

Este trabalho analisa o processo migratório interestadual, focando nos indivíduos mais escolarizados, além das demais características que afetam a decisão de uma pessoa migrar. Os dados, dos anos de 2004, 2009 e 2014 foram extraídos dos microdados da Pesquisa Nacional por Amostra de Domicílios (PNAD) para as 26 unidades da federação e o Distrito Federal. Utiliza-se o modelo probit para o cálculo das probabilidades de o indivíduo migrar, dadas as suas particularidades. Após a investigação, conclui-se que, para os anos considerados, no Brasil quanto mais alta a escolaridade do indivíduo, maior sua probabilidade de migrar.

Palavras-chave: processo migratório, probit, escolaridade.

*Universidade Federal de Viçosa, correos-e: fransuellen.santos@ufv.br, anna.clara@ufv.br, francisco.cassuce@ufv.br, jader.cirino@ufv.br 


\section{Introduçáo}

O movimento migratório na América Latina, assim como em outras partes do mundo possui relação intrínseca entre população e desenvolvimento sendo, em partes, resultante de políticas populacionais. De acordo com Sobral et al. (2012), uma característica marcante da América Latina são as migrações intra-regionais com forças de atração e de expulsão de população. Ademais, o relatório Panorama Social da América Latina 2007, aponta que a migração interna é cada vez mais significativa na América Latina. A pesquisa mostra ainda que esse tipo de migraçáo tem propiciado uma maior consolidação de um sistema menos assimétrico e mais diverso que possibilita um melhor desenvolvimento econômico e social (Cepal, 2007). Atrelado a isso o acesso a melhor educação, saúde e oportunidades de trabalho fazem com que a população de países ou regióes mais pobres se sintam mais propensas a migrar (Sobral et al., 2012).

O Brasil é um país caracterizado por significativo fluxo migratório, que pode ser atribuído, prioritariamente, às amplas desigualdades regionais (Santos Júnior et al., 2005). De acordo com relatório do Instituto Brasileiro de Geografia e Estatística (IBGE), elaborado com base nos dados do Censo 2000 e nas Pesquisas Nacionais por Amostra de Domicílios (PNAD), no período de 1999 a 2004, o número de migrantes atingiu o total de 4.63 milhóes. Mas, de 2004 a 2009, o número absoluto de pessoas que migraram de alguma forma reduziu-se para 3.24 milhóes, o que ainda representa um segmento considerável da população brasileira.

A decisão de migrar dos indivíduos é afetada por uma série de fatores relacionados às suas características pessoais e ao contexto socioeconômico em que estấo inseridos. Um dos principais atributos individuais que influenciam essa tomada de decisão é o grau de escolaridade. Segundo Mendes (2015), durante o período de 2004-2014, o campo educacional foi bastante privilegiado em termos de alocação de recursos federais. A despesa com educação quase quadruplicou em termos reais (corrigidos pela inflação para valores de 2014 - IPCA), sendo no valor de $\mathrm{R} \$ 24.5$ bilhóes em 2004, aumentando significativamente em 2009 para $\mathrm{R} \$ 50$ bilhōes, atingindo R \$ 94.2 bilhões em 2014 .

Percebe-se, nos estudos que apontam uma relação entre educação e migração no Brasil, que o nível de escolaridade é apenas uma das características individuais utilizadas como variável explicativa para analisar a decisão de migrar. Dentre esses estudos, destaca-se Carvalho (2010), que ao verificar os determinantes do fluxo migratório brasileiro, conclui que a probabilidade de migrar está positivamente relacionada ao fato de o indivíduo ser do sexo masculino e à sua escolaridade. Assim, explica que o migrante no Brasil procura sempre uma melhoria na sua qualidade de 
vida, podendo ainda levar em consideração os laços familiares e oportunidades em escolas públicas, o que possibilita eliminar um custo de se educar.

Santos Júnior et al. (2005) e Sachsida et al. (2009) encontraram em suas análises que os migrantes são positivamente selecionados em relação à população como um todo, ou seja, são pessoas mais aptas, motivadas e ambiciosas, bem como possuem nível de escolaridade mais elevado e são mais jovens que a média. Santos Júnior et al. (2005), através dos dados da PNAD de 1999, mostraram que os sujeitos que migram no Brasil ganham, na média, mais do que os não migrantes, além de serem mais produtivos. Além disso, afirmaram que os migrantes, geralmente, saem de locais mais pobres, o que poderia estar agravando fortemente a desigualdade de renda inter-regional.

A partir dessa contextualização, pretende-se com este estudo fornecer embasamento para a análise das migraçóes internas e de sua conexão com a educação, buscando oferecer fundamentos para a estruturação e o aprimoramento de políticas públicas educacionais, como o Programa Universidade para Todos (ProUni), o Reestruturação e Expansão das Universidades Federais (Reuni) e o Fundo de Financiamento Estudantil (Fies). Tais programas são importantes, sobretudo, tendo em vista que, indiretamente, contribuem para a inserção mais adequada dos migrantes no mercado de trabalho.

Ademais, estes programas são fundamentais para a redução das disparidades regionais que forçam os sujeitos a buscar novas oportunidades em localidades diferentes, muitas vezes sobrecarregando as estruturas urbanas das grandes metrópoles. As regióes Sul e Sudeste, as economicamente mais desenvolvidas do país, são mais atrativas devido à concentração da estrutura produtiva que acarreta maior desenvolvimento socioeconômico. $\mathrm{O}$ oposto se verifica em relaçáo à regiáo Nordeste, cuja renda média é inferior à metade da apresentada na região Sudeste (Justo e Neto, 2006).

Dada a importância da migração e dos possíveis diferenciais de mobilidades causadas pelo grau de educação no Brasil, o objetivo deste trabalho é obter as probabilidades estimadas de migrar para as pessoas com maior escolaridade, na faixa etária de 23 a 60 anos, nos diferentes estados brasileiros. Optou-se por utilizar as PNAD de 2004, 2009 e a de 2014, com o objetivo de realizar uma análise de estática comparativa. Essa escolha tem como objetivo verificar como os aumentos de investimento ocorridos no campo educacional para ampliação de vagas podem ou não ter afetado de alguma forma, ano a ano, a probabilidade de migrar. Espera-se que os resultados alcançados contribuam para a literatura nacional nessa área, que apresenta considerável lacuna no que diz respeito à relação entre nível educacional e migração. 


\section{Revisáo de literatura}

\subsection{Teorias da migraçáo}

Um dos primeiros estudos sobre migração, realizado por Ravenstein (1885), considerava os deslocamentos como um estímulo ao crescimento industrial, ao mesmo tempo em que contribuiriam para a melhoria da qualidade de vida dos migrantes. Formulou diversas leis sobre o tema, tratando-se uma das essenciais a de que existe "o desejo inerente dos homens de superar-se em aspectos materiais", sendo ainda utilizada como o principal impulso da migração. Além disso, mostra que nos municípios mais próximos, as mulheres eram mais propensas a migrar que os homens, mas que eles se aventuravam mais.

Um trabalho importante e amplamente citado nessa área é o de Sjaastad (1962), no qual considera o processo migratório como uma forma de investimento em capacitação por parte do indivíduo. Os rendimentos futuros dos sujeitos são condicionados ao seu estoque de capacidade e conhecimento. Assim, a decisão de migrar é determinada pela possibilidade de benefícios esperados superiores aos custos de migrar, no intuito de maximizar o valor de sua utilidade no ciclo de vida.

Lee (1966) avança sobre a teoria espacializada de Ravenstein (1885) e desenvolve uma "sociologia econômica" da migração, na qual afirma que a decisão de migrar é consequência da necessidade do sujeito de sair da pobreza no lugar de origem, impulsionado pela perspectiva de obter rendas elevadas no lugar de destino, assim como a intervençâo de outros obstáculos e fatores pessoais. O autor, então, elabora os conceitos de pull e push, relacionados à migração. Para ele, qualquer lugar teria, de acordo com a perspectiva do migrante, fatores de atração ( $p u l l)$ e repulsão (push). Esses aspectos seriam econômicos, sociais e políticos, relativos aos custos da migração, além de características intrínsecas ao indivíduo. Os fatores responsáveis pela mudança seriam por si só um mecanismo de seleção dos migrantes.

Subsequentemente, Harris e Todaro (1970), dentro do espectro da teoria neoclássica da migração, que é a mais antiga sobre este tema, e considera que existem diferenças inter-regionais de salários reais, o que faz com que a mão de obra tenda a migrar das regióes de baixos salários para aquelas com maiores, propóem alguns avanços em relaçáo à teoria tradicional. Eles adotaram um modelo de dois setores - rural e urbanopara tentar explicar o quê, segundo eles, não era factível com os modelos econômicos tradicionais, de equilíbrio de longo prazo via ajuste de preços e salários. Em sua análise, buscaram explicações para os grandes fluxos 
migratórios do meio rural para o urbano no período, ainda que os ganhos aparentemente fossem menores nas cidades do que no campo.

Borjas (1987) procedeu a uma análise para os Estados Unidos, identificando as diferenças salariais entre os migrantes de diferentes países de origem. Esse estudo tornou-se relevante, sobretudo, porque destacou a importância de características náo observadas dos migrantes para explicar o diferencial de renda que há entre pessoas com habilidades semelhantes. Uma observação a ser realçada é que os migrantes têm em comum a escolha de ter migrado, e isso por si só os diferencia do restante da população. De acordo com o estudo, essa escolha pode estar relacionada às características intrínsecas que corroboram positivamente para salários mais elevados.

Outra corrente de teóricos da migração, à qual se convencionou chamar "Novos Economistas da Migração do Trabalho", trata esse fenômeno a partir de uma perspectiva distinta, considerando que as decisóes em relação à migração não são tomadas de maneira totalmente individual, mas sim pelo domicílio ou por pequenos grupos de pessoas que estão, de alguma forma, ligadas. Stark e Taylor (1989) destacam o conceito de privação relativa na decisão de migrar. De acordo com eles, os grupos familiares consideram sua posição social no contexto em que vivem de modo comparativo a um grupo de referência, que inclui as demais famílias com as quais convivem. A decisão de migrar ou não e o destino seriam definidos com base no retorno potencial do processo migratório, ou seja, espera-se uma posição relativa mais elevada na distribuição de renda. Sasaki e Assis (2000) concordam com esse ponto de vista, indicando que a decisão de migrar (ou não migrar) seria uma decisão coletiva (em família), não estando apenas relacionada a fatores de retorno financeiro.

O estudo de Massey e Aysa-Lastra (2011) explora como o capital social e o humano interagem com os custos de migração na determinaçáo da migraçáo internacional. Os autores explicam que um conjunto de laços familiares fortes e de amizade fracos fazem parte da rede de migrantes de uma pessoa. Estes laços sociais unem os migrantes e os náo migrantes e formam-se vias transmissoras de recursos necessários para a adaptação do migrante no destino, da mesma forma no local de origem estimulam o migrante potencial a ingressar nesse fluxo. Desta forma, um migrante com experiência prévia que possui um vínculo social com um aspirante a migrante tende a oferecer uma valiosa fonte de capital social ao indivíduo, isto quer dizer que a pessoa pode utilizar desse capital social e obter boas informaçóes, assistência material e suporte moral, isto o ajuda a reduzir custos e riscos de migração internacional. Neste sentido, a medida que aumenta os migrantes em uma comunidade há um forte aumento na probabilidade das demais pessoas migrarem. 
Por se considerar uma migração internacional, Massey e Aysa-Lastra (2011) concluem que o tamanho do efeito desse capital social individual sobre a migração dependerá da distância do destino e do tipo de laço que o potencial migrante tem com aqueles que já possuem experiência. Assim, tem-se que os laços fortes (ligação direta com a pessoa migrante) se tornam mais poderosos quando a distância é maior, ao passo que os laços fracos (migrantes da comunidade) reduzem seu efeito de acordo com a distância.

Atualmente, na literatura nacional, dispóe-se de razoável bibliografia que tenta explicar a decisão de migrar dos brasileiros. Em sua maioria, o foco está em quais são as principais características e mudanças da migração. E como mostra o trabalho de Cunha (2005), as transformaçóes não dizem respeito apenas às tendências históricas, mas também à intensificação e ao surgimento de determinados processos que até então eram encobertos pelas migraçóes interestaduais, em especial aquelas da espécie rural-urbana.

Justo e Neto (2006) esclarecem que o migrante brasileiro em sua maioria é aquele que advém de uma unidade federativa de condição social relativamente precária. Conforme os autores, quem migra apresenta um perfil diverso do não migrante, e essa diferença é causada principalmente pela escolaridade, a idade e o sexo. Porém, são as disparidades regionais de oportunidades econômicas que podem explicar a maioria dos movimentos interestaduais do país.

Golgher (2012) realizou um estudo para o Brasil, baseado nas teorias do capital humano e no modelo de Roy, tendo como foco principal os segmentos mais pobres. A partir de modelos de simulaçáo e do modelo logit multinomial, concluiu que há uma espécie de armadilha, na qual esses sujeitos estáo presos. Ou seja, pessoas que vivem em áreas rurais e têm renda muito baixa dispóem de opçóes reduzidas em relação à migração, tanto no que diz respeito à escolha de migrar ou não, quanto aos possíveis locais para os quais se deslocar.

\subsection{Migraçáo e educaçáo}

Há considerável literatura internacional, que relaciona o tema da migração a fatores educacionais, porém o mesmo não se verifica no âmbito nacional. Na literatura estrangeira tem-se o estudo de Becker (1993), que fundamentou seu trabalho sobre migração na Teoria do Capital Humano, considerando que os agentes avaliam racionalmente todas as suas atitudes, calculando o custo-benefício delas. Logo, a decisão de migrar também estaria sujeita a esse tipo de cálculo racional. Além disso, a adaptação dos migrantes em seu destino sofreria influência das decisóes que eles tomam, sendo que, quando há perspectiva de aumento de ganhos, eles buscam 
investir mais, por exemplo, em educaçáo, a fim de aumentar o capital humano.

Um dos primeiros trabalhos que demonstram essa relação no Brasil foi realizado por Martine (1990), que percebeu mediante suas pesquisas que os migrantes se movem há muito tempo da área rural em direção às cidades onde há maior concentração industrial. Destacam que em meados dos anos 60, quando houve forte desruralização, a tecnologia estava aumentando sua participação no campo; além disso, um mecanismo diferente de crédito foi adotado, afetando duramente os pequenos produtores, pois o mercado deixou de absorver mão de obra de baixa qualificação, e conjuntamente a isso as cidades de destino possuíam os salários mais elevados.

Em geral, os custos de mobilidade são mais altos para os trabalhadores com menor escolaridade, bem como eles também são menos flexíveis (Bound e Holzer, 2000). Além disso, ao analisar a migração interna dos Estados Unidos, Basker (2002) verificou que existe uma relação positiva entre a educação e a mobilidade, porém negativa com a idade. Assim, ele conclui que pessoas com maior qualificação possuem maior probabilidade de migrar, enquanto as mais velhas têm redução progressiva dessa possibilidade.

De acordo com Patarra (2003), pode-se esquematizar etapas migratórias que procuram retratar a dinâmica da migração interna no Brasil. Essas etapas são os principais fluxos de volume de deslocamento de população cujo principal determinante é o desequilíbrio do desenvolvimento econômico regional. Logo, os centros de desenvolvimento econômico atraem populaçôes de regióes menos promissoras, caracterizando o fluxo de mão de obra.

Para Borjas (2008), quando se trata a migração como um investimento em capital humano, os mais jovens tendem a migrar mais facilmente, pois possuem um tempo maior para recuperar esse investimento e, em geral, têm maior grau educacional. Uma vez que detêm maior qualificação, conseguem visualizar melhor as oportunidades em outras regióes, o que de certa maneira reduz o custo que advém da decisão de migrar. $\mathrm{O}$ autor ressalta também que muitas vezes a migração está interligada a motivos econômicos, ou seja, os trabalhadores desejam melhorar suas condiçôes econômicas ou as firmas almejam trabalhadores mais qualificados.

Ao analisar uma reforma educacional ocorrida na Noruega, que aumenta o tempo de escolaridade obrigatória em dois anos, Machin et al. (2012) focam seu estudo em noruegueses com menos de 10 anos de educação formal, e mostram que pessoas com mais escolaridade são mais móveis e em geral fazem escolhas de migração melhores do que os com menor instrução. Similarmente, Weiss (2015) verifica uma reforma que 
aconteceu na Europa, demonstrando que as pessoas que são induzidas pela reforma escolar a obter um ano a mais de educação possuem maior propensão a migrar (cerca de 16\%) de região em seu país, na faixa etária de 15 a 50 anos.

Tendo em vista a literatura consultada, optou-se neste estudo por uma investigação a respeito da relação entre o nível educacional e a migração. Fatores analisados pelos autores consultados também foram levados em consideração, com objetivo principal de controlar seus efeitos na probabilidade de o indivíduo migrar, e dentre esses enfoques, constam tanto características pessoais intrínsecas quanto da região de origem e destino dos sujeitos.

\section{Metodologia}

\subsection{Modelo probit}

Tendo em vista que o objetivo deste trabalho é verificar o efeito da educação sobre a migração, utiliza-se de um método econométrico que possa analisar de que modo um nível mais elevado de escolaridade afeta a probabilidade de migrar ou não, já que a variável dependente em questão é do tipo binária. Sendo assim, recorre-se a modelos de escolha qualitativa, neste caso optou-se pelo modelo probit que, permite estimar a probabilidade de migrar com base em uma função de distribuição normal acumulada.

Ademais, o modelo probit foi escolhido como método para a estimação neste trabalho por possuir propriedades mais consistentes e eficientes de estimação, como por exemplo, a garantia de que a probabilidade de ocorrência do evento esteja num intervalo entre zero e um, bem como da relação náo linear entre as variáveis explicativas e a probabilidade estimada da variável dependente (Wooldridge, 2002).

O modelo probit utiliza a funçáo de probabilidade normal acumulada criando um índice teórico não observado, dependente das variáveis explanatórias do modelo. De tal modo que, quanto maior o valor deste índice, maior será a probabilidade de o indivíduo migrar, sendo determinado por:

$$
Z_{i}=\beta_{0}+\beta_{1} \text { Superior }+\beta_{2} \text { Medio }+\beta_{3} \text { Fund }+\boldsymbol{\beta} \mathbf{X}_{\mathbf{i}}+\varepsilon_{i}
$$

Onde $\beta_{i}(i=0,1,2,3)$ são os parâmetros do indicador. Como variáveis explicativas tem-se que Superior, Medio e Fund são as dummies que indicam os níveis educacionais dos indivíduos amostrados tendo como cate- 
goria base (de comparação) os não escolarizados ou com ensino fundamental incompleto; e é um vetor de covariáveis que inclui dados como cor do indivíduo, gênero, se possui filho antes de migrar, se é de região urbana, se é da região metropolitana, a renda média proveniente do trabalho no estado de origem e a idade do indivíduo que se encontra entre 23 e 60 anos; e é o termo de erro aleatório.

Com isso, define-se um valor crítico $Z^{*}$, tal que se $Z i>Z^{*} i$, o indivíduo migra (Pindyck e Rubinfeld, 2004). Assim, $Z * i$ será uma variável aleatória com distribuição normal e a probabilidade de $Z i>Z * i$, e poderá ser calculada pela funçáo de probabilidade normal acumulada:

$$
\begin{aligned}
& P_{i}\left(\text { Migracão }=1 \mid \text { Fund, Medio, Superior, } X_{i}\right) \\
& =F\left(Z_{i}\right) \subseteq F\left(\beta_{0}+\beta_{1} \text { Superior } \mp \beta_{2} \text { Medio }+\beta_{3} \text { Fund }+\boldsymbol{\beta} \mathbf{X}_{\mathbf{i}}\right) \\
& =\overline{\sqrt{ } 2 \pi} \int_{-\infty}^{\bar{T}} \beta_{0}+\beta_{1} \text { Superior }+\beta_{2} \text { Medio }+\beta_{3} \text { Fund }+\boldsymbol{\beta} \mathbf{x}_{\mathrm{i}} \mathrm{e}^{-\mathrm{t}^{2} / 2} d t
\end{aligned}
$$

Em que é interpretado como a probabilidade de migrar condicionado ao nível educacional e às demais características do indivíduo. Neste caso, a ocorrência do evento é quando a pessoa migra, ou seja, é um evento certo, que assume valor 1 (um), e se não migra, assume valor 0 (zero). Ademais, $F($.) é a função de distribuição cumulativa normal padrão. Bem como, t é uma variável aleatória com distribuição normal, média zero e variância 1. Ou seja, como enfatizado por Pindyck e Rubinfeld (2004), quanto maior o valor do índice, maior a probabilidade de o evento ocorrer, pois a probabilidade é calculada pela área abaixo da curva normal padrão de a (valor estimado com X específicos).

Como exposto por Cirino (2008), os coeficientes para modelos de escolha binária não possuem significado econômico relevante. Portanto, as informaçôes mais importantes do modelo são as probabilidades e os efeitos marginais das variáveis de interesse. $\mathrm{E}$ ainda, se os valores e sinais dos coeficientes das variáveis explicativas forem conhecidos é possível determinar se o impacto da variável escolhida sobre a probabilidade de migrar é positivo ou negativo.

Espera-se que o efeito de um maior nível de escolaridade sobre a migração seja positivo, de forma que a probabilidade de migrar seja maior para indivíduos com ensino superior completo, seguidos por aqueles com ensino médio e fundamental, respectivamente (Bound e Holzer, 2000; Basker, 2002; Sabbadini e Azzoni, 2006; Machin et al., 2012; Weiss, 2015). Além disso, em relaçáo às características pessoais dos migrantes, supóe-se que as chances de migrar estejam positivamente relacionadas com o fato de o indivíduo ser homem, branco e mais jovem. Considera- 
-se também que famílias maiores terão custos de migração aumentados, de modo que, o fato de possuir filhos irá reduzir a probabilidade de o indivíduo migrar (Basker, 2002; Oliveira e Jannuzzi, 2005; Borjas, 2008; Justo e Neto, 2009).

No que diz respeito à origem dos migrantes, a tendência é supor que a probabilidade de migrar varie inversamente à renda média que recebiam no estado de origem. Tanto os trabalhos que enfatizam a perspectiva sociológica da migraçáo, quanto aqueles embasados na teoria econômica neoclássica, pressupóem que o indivíduo migra impulsionado pela perspectiva de superar as condiçóes de pobreza em seu local de origem e obter melhores salários. Considerando tal realidade, parece natural que a migração ocorra de estados em que os sujeitos possuem renda menor para outros em que a renda média seja maior (Lee, 1966; Harris e Todaro, 1970; Santos Júnior et al, 2005).

Considera-se ainda que residir fora da regiáo metropolitana e em área urbana esteja relacionado a maiores probabilidades de o indivíduo migrar, tendo em vista que ao tomar esta decisão, os indivíduos buscam deixar locais mais precários e com menor infraestrutura em busca de condiçóes melhores. Além disso, a tendência migratória urbana-urbana se intensificou nos últimos anos (Rigotti e Vasconcellos, 2005; Santos Júnior et al., 2005; Golgher, 2006; Justo e Neto, 2009).

\subsection{Fontes de dados e variáveis empregadas}

Os dados utilizados de migração foram retirados das PNAD 2004, 2009 e 2014. Essa pesquisa é realizada anualmente, com exceção dos anos censitários, e consiste em uma amostra probabilística de domicílios que abrange todo o território nacional (Cirino, 2008; IBGE, 2011). Neste sentido, a PNAD possui um Plano de Seleção Amostral Complexo, envolvendo características de amostragem estratificada e conglomerada. Destarte, para que sejam produzidos estimadores eficientes, consistentes e não viesados, que incorporem tais características, deve-se levar em conta a natureza da seleçáo.

Cunha (2010) destaca que através da PNAD é possível identificar pelo menos três diferentes origens do migrante. O primeiro é o caso da "UF de nascimento", em que o sujeito é definido como migrante se a Unidade Federativa em que ele foi entrevistado é diferente daquela onde nasceu, independentemente do seu tempo de residência, de forma que alcança apenas os migrantes acumulados conhecidos como lifetime migrants. Utilizar este quesito exige um controle pelo tempo de residência e, inevitavelmente, pode ocorrer uma análise de cortes migratórios muito dispersos no tempo, e assim, muito distintos na questão dos processos. 
O segundo item descrito por Cunha (2010) é a "UF de residência anterior", que é basicamente a última origem do indivíduo antes de fixar residência no estado onde foi entrevistado, o que até fornece uma informação mais atualizada da migração. Por último, tem-se a "UF de residência cinco anos antes", que também permite conhecer movimentos mais recentes dos sujeitos, mas o diferencial é que estabelece claramente um período para a migração, no caso cinco anos. Utilizando qualquer um dos três quesitos, é possível definir os fluxos migratórios em nível das UFs. Neste estudo escolheu-se, para fins de identificação dos fluxos migratórios interestaduais, a última opção, que segundo Ojima e Fusco (2015) também é conhecida como migrante de data fixa, pois combina o espaço (UF) e o tempo (cinco anos atrás).

A amostra ${ }^{1}$ utilizada é constituída por indivíduos entre 23 e 60 anos de idade, o que foi realizado no intuito de tentar se aproximar dos cortes de indivíduos utilizados em estudos como o de Weiss (2015) e Carvalho (2010). Esta seleção parte da ideia de tentar captar as pessoas que migraram por conta própria, ou seja, como a variável de migração estudada é de data fixa ( 5 anos), o sujeito mais jovem migrou quando tinha pelo menos 18 anos, então, considera-se que tem plenas condiçóes de migrar não apenas para acompanhar sua família. Enquanto isso, na faixa mais avançada da idade, optou-se por eliminar aqueles que já são aposentados e que migram muitas vezes por questóes de saúde.

Também foram retiradas da amostra aquelas pessoas que migraram para outro país, pois envolve probabilidades diferentes da migração interna (Machin et al., 2012). Conforme exposto por Sabbadini e Azzoni (2006), devido às diferenças econômicas ou sociais entre as regióes de um país, além de menores impedimentos legais, institucionais e culturais, é de se esperar que as migraçóes internas sejam mais intensas do que as internacionais.

A fim de garantir informaçóes mais precisas para a variável $R M \_n a s c$, faz-se necessário a exclusão das pessoas com renda per capita do trabalho igual a zero e as com valor maior do que $\mathrm{R} \$ 30,000$, esse recorte foi feito seguindo a ideia de Hoffmann e Ney (2008). Portanto, como explicam os autores, a exclusão de valores das caudas inferiores e superiores consegue eliminar boa parte das pessoas extremamente pobres e aquelas extremamente ricas. Auxilia ainda para que as medidas não sejam subestimadas, ou seja, garante maior coerência e precisão das informaçóes, visto que alguns indivíduos com rendimento não declarado na PNAD e que vivem da produção para o próprio consumo são considerados sem renda, en-

${ }^{1}$ As amostras são compostas por observaçóes 150,478 em 2004, 161,967 em 2009 e 148,802 em 2014. 
quanto outras podem afirmar uma aproximação fora da realidade. Logo, após esse recorte calcula-se a renda média no estado de origem, que se trata de uma variável per capita construída a partir de informaçóes do rendimento do trabalho principal per capita e do lugar de nascimento da PNAD. Assim, com base nessas informaçóes calcula-se a média da renda do trabalho principal per capita em cada estado de origem.

A variável renda_nasc deseja captar o efeito da renda média dos indivíduos em seu lugar de origem, ou seja, quer verificar se aquelas pessoas com menor renda média no seu estado de origem tendem a migrar mais em busca de melhores condiçóes. Portanto, para a construção dessa variável leva-se em consideração a renda média do trabalho principal per capita em cada estado de origem, de modo que o indivíduo que migrou terá como renda média a que tinha em seu estado de origem.

Com relação às variáveis utilizadas para representar o grau de escolaridade, foram empregadas dummies para indicar os níveis fundamental, médio e superior completos, de forma a permitir o isolamento dos efeitos da educação. Essa opção, em detrimento do número de anos de estudo, foi feita porque o rendimento da educação não é linear, deste modo, o acréscimo de um ano na escolaridade não faz grande diferença, ao contrário da conclusão de cada ciclo.

Por fim, para a variável que representa filhos antes de migrar, foram considerados apenas os com idade entre 5 e 17 anos, que são os que realmente podem afetar a decisão de um sujeito migrar; afinal, com esta idade, a criança/adolescente ainda se encontra sob a responsabilidade dos pais. E como explicam Leslie e Richardson (1961), quanto maior a família, menor a probabilidade de migrar. No quadro 1 , são descritas as variáveis do modelo.

Uma limitação deste trabalho é a questão de como medir o capital social, visto que de acordo com a literatura é um importante determinante da mobilidade dos indivíduos. Mas, dado o formato dos dados utilizados e disponibilizados pela PNAD não foi possível incluir essa variável no modelo analisado, pois não há uma boa proxy nesta base que capte o efeito do capital social sobre a migração dos indivíduos.

Para testar se os modelos estimados apresentam propriedades estatísticas consistentes e que as inferências estatísticas sobre a amostra estáo corretas, fez-se uso de alguns aportes econométricos, sendo eles: o Teste Wald e a Curva ROC. O primeiro serve para verificar se o modelo utilizado possui significância global. É empregado justamente quando se trabalha com amostra complexa, que é o caso da PNAD (Fávero e Belfiore, 2014). Através de uma estimativa apropriada da variância, este teste é capaz de demonstrar as características implícitas em um plano amostral complexo, com vistas a fornecer uma estatística de teste válida assintoti- 


\section{Quadro 1}

\section{Descrição das variáveis}

\begin{tabular}{|c|c|c|}
\hline $\begin{array}{l}\text { Variáveis do } \\
\text { modelo }\end{array}$ & $\begin{array}{l}\text { Variáveis originárias ou } \\
\text { selecionadas da PNAD }\end{array}$ & Descriçâo \\
\hline Migração & $\begin{array}{l}\text { Morava na Unidade da Fede- } \\
\text { raçáo há } 5 \text { anos da data de } \\
\text { referência }\end{array}$ & $\begin{array}{l}\text { Variável binária que assume valor } \\
\text { um se o indivíduo não morava na } \\
\text { Unidade da Federação há } 5 \text { anos da } \\
\text { data de referência e zero caso con- } \\
\text { trário. }\end{array}$ \\
\hline $\begin{array}{l}\text { Fund, Medio e } \\
\text { Superior }\end{array}$ & Anos de estudo & $\begin{array}{l}\text { Classificaçáo estabelecida em funçáo } \\
\text { do último nível completo alcançado } \\
\text { pela pessoa, ou seja, fundamental, } \\
\text { médio ou superior. }\end{array}$ \\
\hline Branco & Cor ou raça & $\begin{array}{l}\text { Dummy com base na característica } \\
\text { de cor ou raça declarada pela pessoa, } \\
\text { que assume valor } 1 \text {, se o indivíduo } \\
\text { se autodeclara branco, e } 0 \text {, caso } \\
\text { contrário. }\end{array}$ \\
\hline Urbano & Situação do domicílio & $\begin{array}{l}\text { Dummy que assume valor } 1 \text { se o } \\
\text { indivíduo é da área urbana, e } 0 \text { se } \\
\text { rural. }\end{array}$ \\
\hline Homem & Gênero & $\begin{array}{l}\text { Dummy, que assume valor } 1 \text { se o } \\
\text { indivíduo é do sexo masculino, e } 0 \\
\text { se for do sexo feminino. }\end{array}$ \\
\hline Filho5_17 & $\begin{array}{l}\text { Condição na família, idade e } \\
\text { tipo de família }\end{array}$ & $\begin{array}{l}\text { Dummy que assume valor } 1 \text { para } \\
\text { aquele indivíduo com filho, com } \\
\text { idade entre } 5 \text { e } 17 \text { anos, e } 0 \text { caso } \\
\text { contrário. }\end{array}$ \\
\hline$R M \_n a s c$ & $\begin{array}{l}\text { Rendimento mensal do tra- } \\
\text { balho principal para pessoas } \\
\text { de } 10 \text { anos ou mais de idade } \\
\text { e Lugar de nascimento }\end{array}$ & $\begin{array}{l}\text { Variável construída a partir da renda } \\
\text { média do trabalho principal per ca- } \\
\text { pita em cada estado de origem dos } \\
\text { indivíduos. }\end{array}$ \\
\hline Idade & Idade & $\begin{array}{l}\text { Foram selecionados indivíduos de } \\
23 \text { a } 60 \text { anos. }\end{array}$ \\
\hline Metropole & Código de área censitária & $\begin{array}{l}\text { Variável dummy que assume o valor } \\
1 \text { se o indivíduo reside em regiáo } \\
\text { metropolitana, e } 0 \text { caso contrário. }\end{array}$ \\
\hline
\end{tabular}

Fonte: elaborado pelos autores com base na PNAD 2004, 2009 e 2014. 
camente (Pessoa e Silva, 1998). Tem como hipótese nula a afirmativa de que todos os coeficientes dos regressores são estatisticamente iguais a zero, ou seja, sem interaçóes entre as variáveis independentes e dependentes.

Para verificar a capacidade do modelo estimado em discriminar as categorias da variável de resposta, neste caso, de migrar ou não, utiliza-se a curva ROC (Receiver Operating Characteristic). De acordo com Braga (2000) e Fávero e Belfiore (2014), estas curvas permitem verificar eficientemente a relação entre os verdadeiros positivos (sensitivity) e os falsos positivos (specitivity). Resulta que, na reta de $45^{\circ}$ a probabilidade de o evento ocorrer é igual à probabilidade de ele não ocorrer. É a curva que representará a combinaçáo das taxas de verdadeiros positivos e falsos positivos. Quanto mais longe a curva está da reta que sai da origem, mais bem estimado é o modelo.

\section{Resultados}

\subsection{Análise descritiva dos resultados}

A análise do perfil da população brasileira, no que se refere aos dados de migração, apresenta resultados que merecem destaque. Houve redução significativa do percentual de migrantes interestaduais em relação ao total da população, ao longo do período analisado. Em 2004, a população era composta por $2.52 \%$ de migrantes, teve uma queda em 2009 alterando-se para $1.72 \%$, enquanto em 2014 , esse percentual elevou-se para $1.82 \%$.

Percebe-se, assim, que vem ocorrendo significativa redução do fluxo migratório interestadual (tabela 1), resultado que corrobora a literatura nacional. Dentre os estudos que apontam nessa direção, pode-se citar o trabalho de Brito et al. (2004), de acordo com o qual, após 1980, os saldos migratórios, bem como as taxas líquidas de migração, têm se reduzido no Brasil. A alteração no padrão migratório, de acordo com o autor, tem dentre suas principais explicaçôes mudanças na economia e na sociedade brasileira.

O perfil do migrante sofreu pequenas alterações no decorrer desses anos, como observa-se na tabela 2. Quanto à situação do domicílio, se localizado em área urbana ou rural, o percentual de migrantes que estavam em áreas urbanas apresentou uma ligeira elevação, pois em 2004 era de $87.87 \%$ indo para $90.49 \%$ em 2014 . Ao passo que, com relação a região metropolitana, a maior proporção de mobilidade encontra-se nos residentes de áreas não metropolitanas.

A variação em relação ao gênero do migrante também foi bem pequena, ao passo que apesar da tendência positiva, a proporção de mulheres 


\section{Tabela 1}

Percentual de migrantes e não migrantes na populaçáo brasileira

\begin{tabular}{llr}
\hline & \multicolumn{1}{c}{ Cano } & \multicolumn{1}{c}{ Brasil } \\
\hline $\mathbf{2 0 0 4}$ & Total & 150,478 \\
& Migrantes & $2.52 \%$ \\
$\mathbf{2 0 0 9}$ & Não migrantes & $97.48 \%$ \\
& Total & 161,967 \\
& Migrantes & $1.72 \%$ \\
& Não migrantes & $98.27 \%$ \\
& Total & 148,802 \\
& Migrantes & $1.82 \%$ \\
& Não migrantes & $98.18 \%$ \\
\hline
\end{tabular}

Fonte: elaborado pelos autores com base nos dados das PNAD 2004, 2009 e 2014.

que migram ainda é relativamente menor se comparada à dos homens. Esse resultado corrobora estudos anteriores, como por exemplo, o de Justo e Neto (2009), no qual mostraram ser maior a proporção de homens mais jovens entre os migrantes do que no restante da populaçáo. No que diz respeito à raça dos indivíduos da amostra, em 2004 e 2009 nota-se que a maioria era branca, enquanto em 2014 essa proporçáo se inverte. O percentual de pessoas brancas dentre os migrantes apresenta queda ao longo dos anos. Mas, faz-se oportuno mencionar que a composição total da população também sofreu mudança significativa, com aumento do percentual de indivíduos que se autodeclaram negros. Este fato pode ter se dado, de acordo com Osório (2003), em consequência de movimentos culturais para maior valorização da negritude.

Ao desagregar a análise por regióes, nota-se que os migrantes que se destinam às regiōes Sudeste e Sul do país eram em sua maioria brancos; em contrapartida, os que se destinavam às regióes Centro-Oeste, Norte e Nordeste eram, em sua maioria, indivíduos não brancos (tabela 3). Estes resultados corroboram Justo e Neto (2009), que mostraram haver uma diferenciação entre os migrantes segundo as regióes de destino no que diz respeito à escolaridade e à raça. Ainda segundo eles, as diferenças regionais de acordo com a escolaridade são bem menores do que as que se percebe através da raça. No entanto, conforme Sachsida et al. (2009) a raça dos migrantes segue a distribuição da população brasileira. Neste sentido, Gama e Machado (2014) apontam que em média os não brancos 


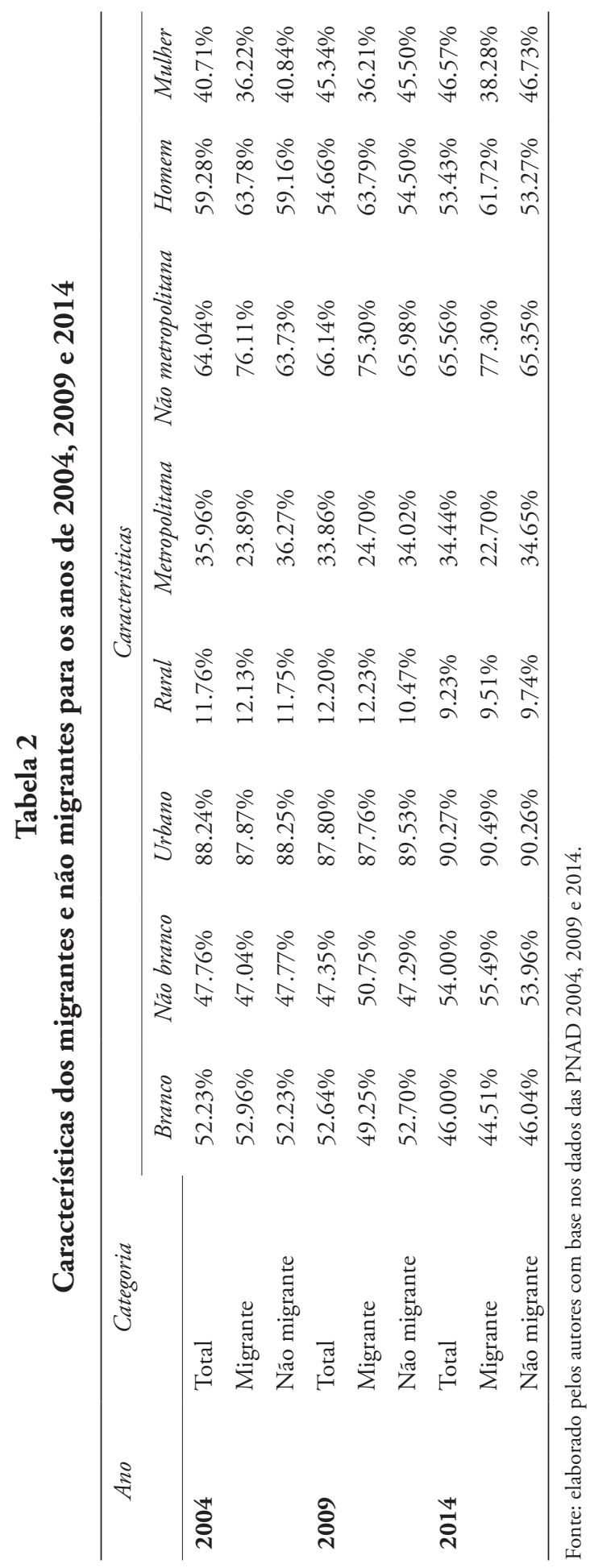




\section{Tabela 3}

\section{Raça e escolaridade por regiáo}

\begin{tabular}{|c|c|c|c|c|c|c|c|}
\hline & & & \multicolumn{5}{|c|}{ Regiāo de destino do migrante } \\
\hline & & & Sudeste & Sul & Centro-oeste & Norte & Nordeste \\
\hline \multirow[t]{5}{*}{2004} & \multirow[t]{2}{*}{ Raça } & Branca & $60.49 \%$ & $80.66 \%$ & $49.77 \%$ & $33.79 \%$ & $36.62 \%$ \\
\hline & & Nấo branca & $39.51 \%$ & $19.34 \%$ & $50.23 \%$ & $66.21 \%$ & $63.38 \%$ \\
\hline & \multirow{3}{*}{ Escolaridade } & Fundamental & $10.23 \%$ & $13.15 \%$ & $9.78 \%$ & $6.76 \%$ & $8.64 \%$ \\
\hline & & Médio & $22.71 \%$ & $21.94 \%$ & $18.19 \%$ & $22.41 \%$ & $16.39 \%$ \\
\hline & & Superior & $15.82 \%$ & $18.24 \%$ & $14.62 \%$ & $13.40 \%$ & $10.96 \%$ \\
\hline \multirow[t]{5}{*}{2009} & \multirow[t]{2}{*}{ Raça } & Branca & $53.65 \%$ & $72.35 \%$ & $44.20 \%$ & $32.47 \%$ & $34.82 \%$ \\
\hline & & Não branca & $46.35 \%$ & $27.65 \%$ & $55.80 \%$ & $67.53 \%$ & $65.18 \%$ \\
\hline & \multirow[t]{3}{*}{ Escolaridade } & Fundamental & $9.60 \%$ & $9.49 \%$ & $7.21 \%$ & $7.73 \%$ & $8.27 \%$ \\
\hline & & Médio & $31.32 \%$ & $28.17 \%$ & $26.04 \%$ & $22.93 \%$ & $25.14 \%$ \\
\hline & & Superior & $17.87 \%$ & $22.38 \%$ & $18.38 \%$ & $21.20 \%$ & $10.95 \%$ \\
\hline \multirow[t]{5}{*}{2014} & \multirow[t]{2}{*}{ Raça } & Branca & $46.79 \%$ & $65.31 \%$ & $37.45 \%$ & $32.43 \%$ & $35.06 \%$ \\
\hline & & Não branca & $53.21 \%$ & $34.69 \%$ & $62.55 \%$ & $67.57 \%$ & $64.94 \%$ \\
\hline & \multirow[t]{3}{*}{ Escolaridade } & Fundamental & $8.31 \%$ & $11.41 \%$ & $9.04 \%$ & $5.65 \%$ & $8.11 \%$ \\
\hline & & Médio & $28.79 \%$ & $28.86 \%$ & $28.81 \%$ & $34.86 \%$ & $32.72 \%$ \\
\hline & & Superior & $23.02 \%$ & $23.61 \%$ & $17.24 \%$ & $14.47 \%$ & $10.99 \%$ \\
\hline
\end{tabular}

Nota: contas do nível educacional não fecham em $100 \%$, pois são considerados apenas os ciclos completos.

Fonte: Elaborado pelos autores com base nos dados das PNAD de 2004, 2009 e 2014.

possuem menor probabilidade de migrar, bem como são menos escolarizados que os brancos. O que leva a outras questóes, pois se a pessoa é mais qualificada e, assim, mais informada acaba procurando melhores ocupaçóes no mercado de trabalho, ou seja, buscam melhorias na qualidade de vida. No que se refere à escolaridade, quando se verifica a porcentagem de pessoas com educação superior e médio completa, em sua maioria migraram para as regiôes Sul e Sudeste.

Conforme mostra a tabela 4, a idade média dos migrantes sofreu elevação quase insignificante ao longo dos anos. Houve, entre 2004 e 2014, uma tendência positiva nos rendimentos no Estado de origem dos que migraram, saindo de $\mathrm{R} \$ 1194.30$ em 2004 e atingindo o valor de R\$1662.67 em 2014 (renda média per capita calculada a preços de 2014, corrigidos pelo IPCA). Apesar do aumento, estes valores ainda são menores do que os rendimentos dos não migrantes. Ou seja, a renda menor em seu lugar de origem é um impulsionador de migração, este resultado vai de encontro ao estudo de Santos Júnior et al. (2005), que explica que 


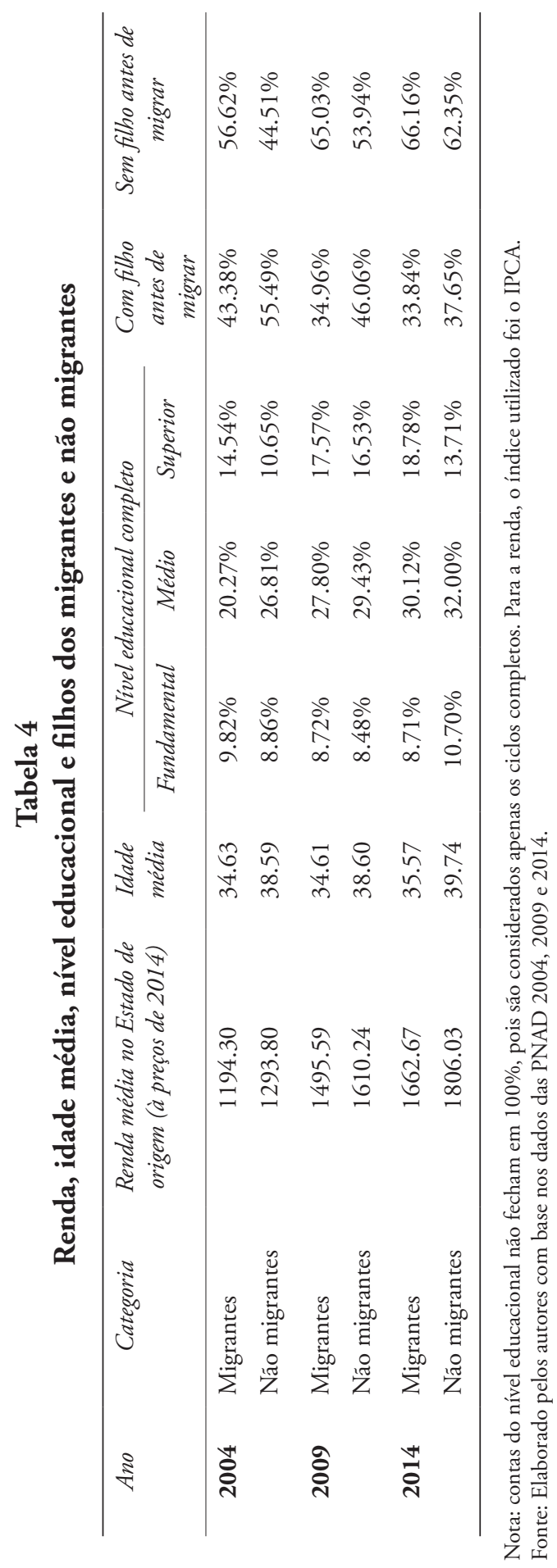


no Brasil a migração ocorre em média de estados com menor renda per capita para aqueles com maiores rendas. Os autores ressaltam ainda que os migrantes brasileiros são mais aptos, ambiciosos e motivados.

Quanto à educação dos migrantes, pode-se perceber que no período analisado houve aumento considerável na proporção dos que possuem níveis médio e superior completos pari passu a redução daqueles com ensino fundamental completo. Com isso, verifica-se que os migrantes brasileiros têm sido pessoas com grau de educação mais elevado, em comparação aos anos anteriores. Em relação a ter ou não filho antes de migrar constata-se que nestes anos os migrantes, em sua maioria, não possuíam filhos.

\subsection{Ajustamento do modelo}

Partindo para uma análise estatística, primeiramente é necessário garantir que a estimação obedeça às propriedades estatísticas consistentes. $\mathrm{O}$ primeiro teste realizado será o teste de Wald para identificar a significância global do modelo. Os resultados para todos os anos encontram-se na tabela 5. Logo, verifica-se que ao nível de significância de $1 \%$ rejeita-se a hipótese nula, e assim a relação estudada é significativa, isto é, os modelos estariam bem especificados.

\section{Tabela 5}

Teste de Wald dos modelos probit para os anos de 2004, 2009 e 2014

\begin{tabular}{lcc}
\hline \multirow{2}{*}{ Ano } & \multicolumn{2}{c}{ Teste de significancia global do modelo } \\
\cline { 2 - 3 } & \multicolumn{2}{c}{ Teste de Wald } \\
\cline { 2 - 3 } & Valor calculado & Prob>Chi ${ }^{2}$ \\
\hline $\mathbf{2 0 0 4}$ & 1023.33 & 0.0000 \\
$\mathbf{2 0 0 9}$ & 1015.48 & 0.0000 \\
$\mathbf{2 0 1 4}$ & 1011.00 & 0.0000 \\
\hline
\end{tabular}

Fonte: elaborado pelos autores com base nos dados das PNAD 2004, 2009 e 2014.

Para avaliar de modo eficiente a relação entre a especificidade e sensitividade utiliza-se a Curva ROC, onde é possível verificar a capacidade preditiva e o ajuste do modelo. (Cameron e Trivedi, 2010; Fávero e Belfiore, 2014). O teste indica que, para todos os anos, o poder discriminatório dos modelos é considerado satisfatório, ou seja, possuem boa capacidade preditiva tanto em relação à sensibilidade quanto à especificidade. 
Portanto, o modelo ajustado para o ano de 2004, possui uma área no valor de 0.6660; para o ano de 2009 de 0.6816; e para 2014, de 0.6764 .

\subsection{Análise da probabilidade de migraçáo no Brasil}

Tendo em vista a análise descritiva da amostra e os testes que apontam que os modelos estimados apresentaram bom ajustamento, cabe proceder a discussão de resultados. São gerados três modelos para a investigação em questão, mas cabe destacar que no modelo probit os coeficientes estimados não possuem significados econômicos relevantes, desta forma, optou-se por apresentar os efeitos marginais $(\mathrm{EMg})$ no ponto médio amostral - Vide tabela 6.

A coluna (1) apresenta um modelo básico em que são incluídas apenas as dummies que representam escolaridade dos indivíduos. Percebe-se através dos $\mathrm{EMg}$ que há uma correlação positiva entre o acréscimo de um nível de escolaridade e a probabilidade de migrar. Dessa forma, um indivíduo com ensino superior possui maiores chances de migrar do que os demais níveis. Isso ocorre porque os mais qualificados ponderam melhor as oportunidades provenientes do deslocamento do lugar de origem, além de possuírem um custo de mobilidade menor. Verifica-se, portanto, que os indivíduos com graduação completa apresentam as chances de migração superior aos demais níveis (Borjas, 2008; Justo e Neto, 2009; Machin et al., 2012).

$\mathrm{Na}$ sequência, são acrescentados à estimação as variáveis que indicam características individuais e demográficas (coluna 2), sendo elas: sexo, cor, idade, zona urbana e área metropolitana. Constata-se que sob os efeitos marginais das variáveis de escolaridade não se observa alterações significativas, considerando os erros padrão, ou seja, não há diferença significativa entre este modelo e o anterior (coluna 1) quanto a variável ensino superior. Entretanto, durante os anos algumas variáveis perdem a significância estatística enquanto outras tornam-se significativas, como por exemplo, a variável ensino fundamental, que não é significativa nos anos de 2004 e 2009, mas tem efeito no ano de 2014.

Quanto aos efeitos das variáveis acrescentadas, pode-se notar que, em todos os anos, os indivíduos do sexo masculino possuem maiores chances de migração do que as mulheres. A explicação mais plausível para este fato é que os homens são mais dispendidos com relação à família do que as mulheres (Oliveira e Jannuzzi, 2005). O estudo de Justo e Neto (2009) corrobora este resultado ao afirmar que no Brasil os migrantes, em sua maioria, são do sexo masculino.

Ademais, a probabilidade de o indivíduo migrar está inversamente relacionada com a idade, destarte, ao longo desses anos a migração entre 


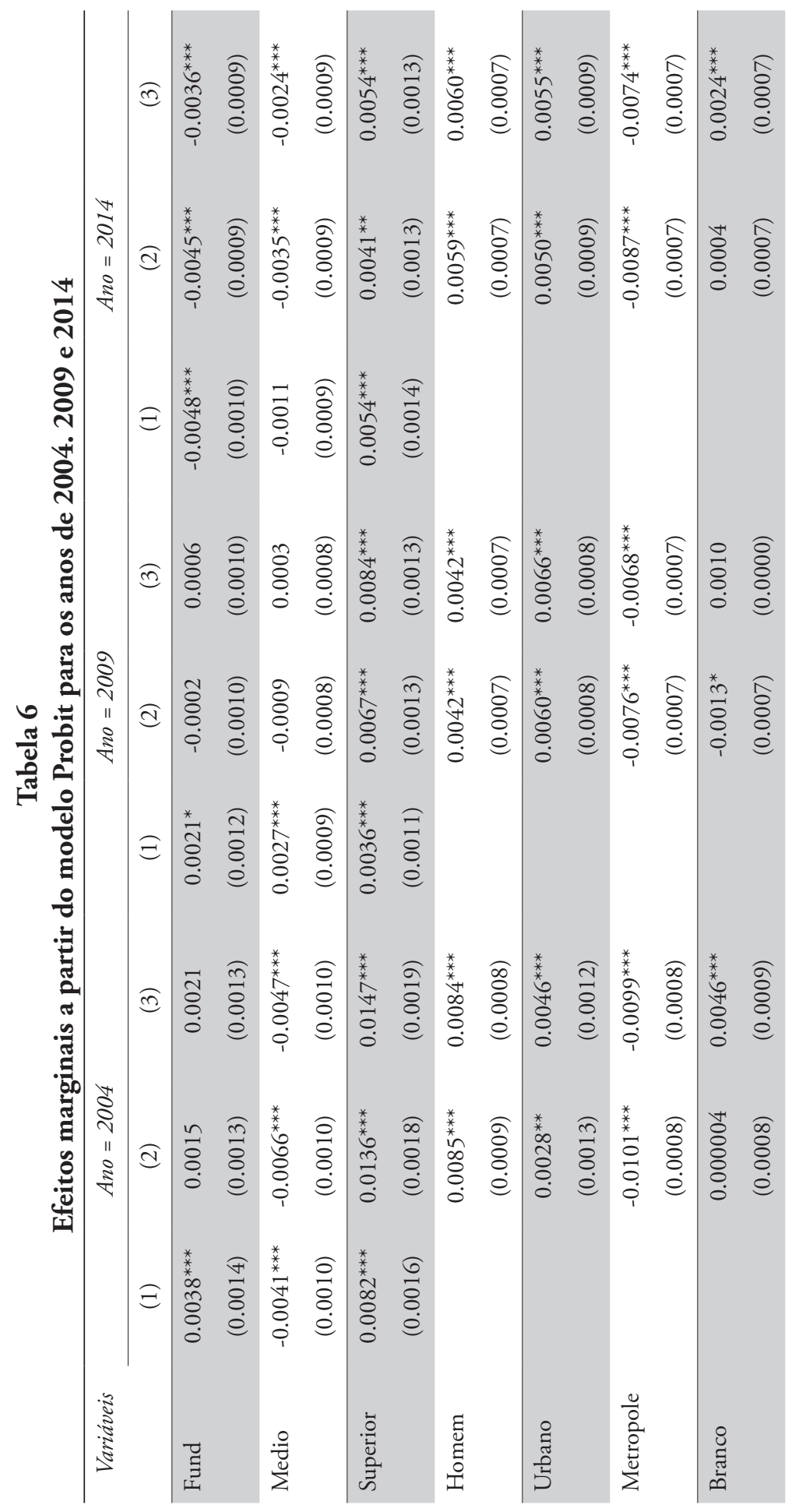




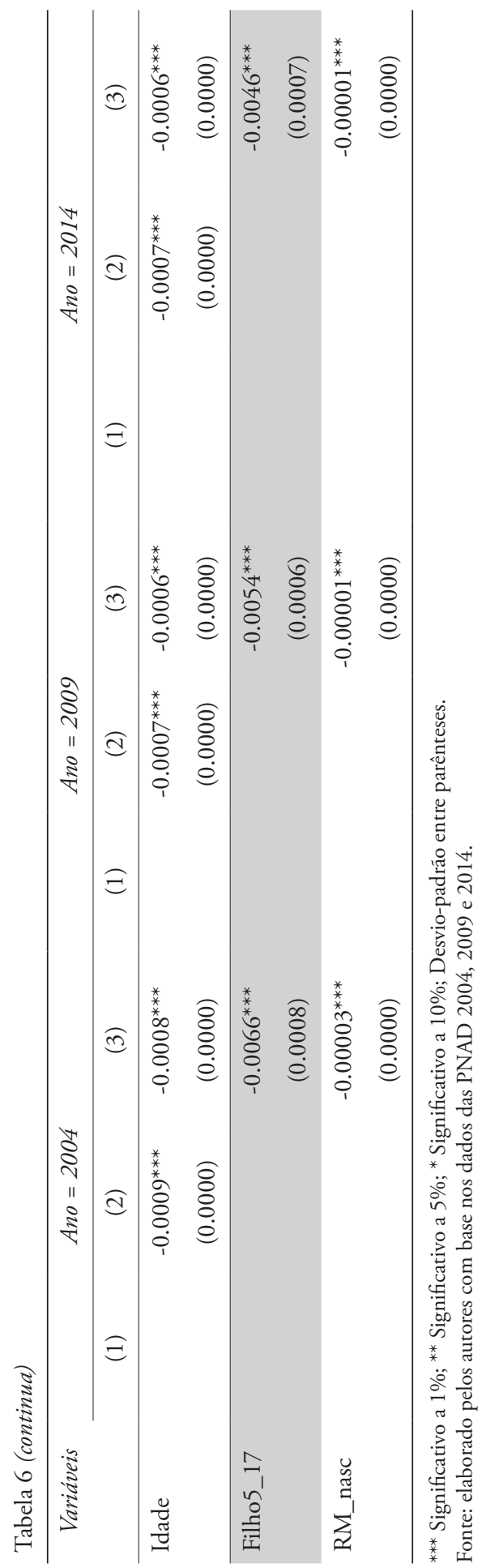


os mais jovens foi mais expressiva para o caso brasileiro. Este resultado corrobora Oliveira e Jannuzzi (2005), em que os jovens, com pouco mais de 20 anos, estariam sujeitos a migrar mais do que qualquer outro grupo etário. Os autores apontam que a elevada concentraçáo de jovens entre os migrantes seria explicada pela maior sensibilidade desse segmento com relação às ofertas de trabalho e de melhores empregos, assim como, pela maior facilidade de adaptação a novas situaçóes e maior desprendimento em deixar seu ambiente de origem. Cabe destacar ainda que a maior probabilidade de migração entre os mais jovens pode também estar atrelada às maiores oportunidades de acesso à educação superior.

Considerando o lugar de residência, verifica-se que as pessoas que residem em regióes metropolitanas associam-se negativamente com a probabilidade de migrar, ou seja, a probabilidade de migrar quando um indivíduo é da região metropolitana é relativamente menor do que daqueles que residem em regióes náo metropolitanas, o que pode estar fortemente ligado à estrutura e qualidade de vida que essas regiôes proporcionam. De acordo com Rigotti e Vasconcellos (2005), as mesorregióes que contêm capitais de unidades da federação ou regióes metropolitanas são aquelas que mais atraem população em seu entorno imediato e, dependendo do peso delas na hierarquia urbana do país, de áreas mais distantes e menos povoadas.

O contrário ocorre com aqueles que são da zona urbana, no qual se verifica que tendem a migrar mais do que os da área rural. Reforçando o estudo de Golgher (2006), segundo o qual, no Brasil a migração do tipo urbano-urbano é a mais numerosa não só no país como um todo, mas também nas regiōes brasileiras. Com relação a raça, nota-se um resultado pouco consistente, visto que apenas no ano de 2009 a variável foi significativa e com sinal negativo.

O modelo apresentado na coluna 3 acrescenta as variáveis relacionadas às características familiares e socioeconômicas dos indivíduos, que dizem respeito, respectivamente, aos filhos que a pessoa tem antes de migrar e à renda média do estado de nascimento. Ao considerar a análise através dos erros padráo percebe-se que o modelo da coluna 3 acompanha a coluna 2. E, novamente, nota-se que não há diferença significativa entre os dois modelos anteriores para os coeficientes estimados para a variável ensino superior. Porém, para a variável de ensino médio o efeito é não significativo no ano de 2009 , enquanto a variável que indica o nível fundamental possui significância apenas no ano de 2014 e sem diferença significativa entre os modelos.

Cabe destaque sobre a variável de cor, pois no modelo 2 a mesma foi significativa e com sinal negativo apenas no ano de 2009, enquanto isso no modelo 3 apresenta efeito significativo e com sinal positivo para os 
anos de 2004 e 2014. Este resultado estabelece que a variável não demonstra muita consistência para explicar a mobilidade dos indivíduos de forma agregada entre os estados. Nesse sentido, para corroborar esta afirmação tem-se o trabalho de Justo e Neto (2009) indicando que está variável possui resultados diferentes de acordo com a região, assim aponta que enquanto ser da raça branca eleva a probabilidade de migração para as regióes Sul e Sudeste, pertencer a tal grupo diminui a probabilidade de migração paras as regiốes Norte, Nordeste e Centro-Oeste.

$\mathrm{O}$ EMg da renda média no estado de origem está associado de forma negativa com a chance de migrar, mas esse efeito é ínfimo, ou seja, um possui pouco efeito sobre a decisão do indivíduo quanto a migração. Nota-se também que os indivíduos que possuem filhos antes do movimento, tendem a migrar menos em comparação àqueles que não possuem, ou seja, o fato da pessoa ter filho é uma barreira a migração, visto que o mesmo pondera mais uma possível mudança por causa da família e de todo o custo de deslocamento. Em todos os anos, a probabilidade de migrar quando já se possui filhos é menor. Os autores Leslie e Richardson (1961) apontam que as famílias maiores têm custos mais elevados para migrar, o que torna mais difícil que isso ocorra. No caso brasileiro, o estudo de Justo e Neto (2006), indica que a presença de filho tende a gerar um conflito entre a proximidade da família e a escolha pelo mercado de trabalho.

Neste estudo, destaca-se a importância da escolaridade, da renda e dos filhos, que são variáveis essenciais que podem influenciar na probabilidade de migrar. Assim, com base nos dados apresentados e nos resultados dos modelos estimados, percebe-se que o padrão migratório vem reforçando, cada vez mais, as desigualdades regionais.

\subsection{Os efeitos do aumento de um nivel de escolaridade na probabilidade de migrar}

A partir do agrupamento dos indivíduos de acordo com seu nível de instrução formal, e tomando como base um cenário de referência, é possível avaliar as probabilidades de migrar ao longo dos três anos estudados e, assim, analisar a partir de uma estática comparativa a evolução do processo migratório no Brasil ao longo destes 10 anos. Cabe destacar que neste período foram implementadas algumas políticas educacionais, principalmente no ensino superior, um deles é o programa de Reestruturação e Expansão das Universidades Federais (Reuni) que afetou significativamente e positivamente o número de vagas na universidade, proporcionando maior acesso.

O indivíduo de referência (cenário referência) apresenta características que se posicionam na média da população ao longo dos três anos. Dessa 
forma, ele possui ensino médio completo, 39 anos de idade, sexo masculino, branco, mora em região não metropolitana, mas é da área urbana, sem filho antes de migrar e com renda média per capita do trabalho principal no estado de origem, a preços de 2014, de $\mathrm{R} \$ 1.803,00$.

No que se refere ao nível de escolaridade, percebe-se que no decorrer dos três anos houve uma redução estatisticamente significativa na probabilidade de migrar (tabela 7). Esse movimento se apresenta mais explícito na passagem de 2004 para 2009. No período entre 2009 e 2014, observa-se que apenas no caso dos indivíduos sem instrução ou com ensino fundamental incompleto constatou-se um leve aumento - estatisticamente significativo- na probabilidade de migrar. Para os demais níveis de escolaridade as probabilidades de migração se mantiveram estatisticamente constantes no período. Além deste fato, pode-se inferir que, comparada aos demais, em todos os anos a probabilidade de migraçáo de indivíduos graduados é estatisticamente mais elevada.

\section{Tabela 7}

Probabilidade de migrar para o cenário referência, segundo o critério dos níveis completos de escolaridade, nos anos de 2004, 2009 e de 2014

\begin{tabular}{|c|c|c|c|}
\hline \multirow[t]{2}{*}{ Categorias } & \multicolumn{3}{|c|}{ Ano } \\
\hline & 2004 & 2009 & 2014 \\
\hline \multirow{3}{*}{$\begin{array}{l}\text { Não escolarizado/ } \\
\text { ensino fundamental } \\
\text { incompleto }\end{array}$} & \multirow{2}{*}{$\begin{array}{c}2.16 \% \\
\text { [I. C. } 95 \%]\end{array}$} & \multirow{2}{*}{$\begin{array}{c}1.32 \% \\
{[\text { I. C. } 95 \%]}\end{array}$} & \multirow{2}{*}{$\begin{array}{c}1.63 \% \\
\text { [I. C. } 95 \% \text { ] }\end{array}$} \\
\hline & & & \\
\hline & $2.03 \%$ & $1.21 \%$ & $1.49 \%$ \\
\hline \multirow[t]{3}{*}{ Fundamental } & $2.38 \%$ & $1.38 \%$ & $1.26 \%$ \\
\hline & [I. C. 95\%] & [I. C. 95\%] & [I. C. 95\%] \\
\hline & $2.15 \%$ & $1.22 \%$ & $1.12 \%$ \\
\hline \multirow[t]{3}{*}{ Médio } & $1.72 \%$ & $1.35 \%$ & $1.39 \%$ \\
\hline & [I. C. 95\%] & [I. C. 95\%] & [I. C. 95\%] \\
\hline & $1.58 \%$ & $1.24 \%$ & $1.28 \%$ \\
\hline \multirow[t]{3}{*}{ Superior } & $3.70 \%$ & $2.15 \%$ & $2.22 \%$ \\
\hline & [I. C. 95\%] & [I. C. 95\%] & [I. C. 95\%] \\
\hline & $3.37 \%$ & $2.35 \%$ & $2.00 \%$ \\
\hline
\end{tabular}

Fonte: elaborado pelos autores com base nos dados das PNAD, 2004, 2009 e 2014.

Entretanto, é possível avaliar que no ano de 2014 a diferença, embora ainda significativa do ponto de vista estatístico, entre os indivíduos graduados e as demais categorias de escolaridade teve uma considerável queda. Neste ano as probabilidades de migrar para as pessoas de maior 
escolaridade na população brasileira se aproximaram das demais parcelas da população. Esse fenômeno poderia ser atribuído ao início de uma crise econômica enfrentada pelo Brasil.

Dada a situação haveria uma queda na oferta de empregos o que afetaria, principalmente, as propostas recebidas pelos trabalhadores mais qualificados da economia, reduzindo as chances de migrarem. Outro ponto é que, em momentos de crise eleva-se as incertezas com relação aos investimentos impactando negativamente nas ofertas de emprego e nas decisóes individuais de investir em outros estados, contribuindo mais uma vez para reduzir as chances dos trabalhadores mais educados migrarem. Quanto ao aumento da migração das pessoas com nível médio essa se deve possivelmente à questão da expansão das universidades, visto que estas pessoas acabam tendo maior oportunidade de dar seguimento aos estudos.

\section{Conclusáo}

Com o objetivo de analisar o processo migratório interestadual no Brasil e suas relaçóes com o nível de ensino formal dos indivíduos, optou-se neste trabalho por um modelo probit, e a partir dele, foram estimados os efeitos marginais. Foram utilizados os microdados das PNAD de 2004, 2009 e 2014 para a elaboração dos modelos. A partir dessa opção, foi possível identificar o impacto dos diferentes níveis de escolaridade para a probabilidade da escolha de migrar do brasileiro, controlando diversas características individuais que poderiam afetar essas probabilidades.

Os resultados encontrados foram relevantes na medida do que se estabeleceu como objetivos do artigo, cabendo enfatizar, entre as conclusóes, alguns achados que revelaram maior impacto. De acordo com a análise realizada, os indivíduos que apresentam maior probabilidade de migrar são aqueles com nível educacional mais elevado, são homens, mais jovens, habitantes de áreas urbanas e residentes em regiôes não metropolitanas. A questão familiar é outra variável que projeta forte influência sobre a probabilidade de migraçáo, ou seja, quem já possui filhos, tende a migrar menos.

As mudanças ocorridas na conjuntura econômica brasileira, ao longo dos últimos anos, fazem com que se torne fundamental analisar os impactos sociais resultantes dessas alteraçóes. Inúmeros projetos governamentais (especialmente de cunho social) podem exercer interferência na decisão de migrar, na medida em que modificam as condiçóes de vida da população. São exemplos dessas açôes os programas de ampliação do acesso ao ensino superior, que podem influenciar a migração com obje- 
tivo de buscar maior qualificaçáo através da educação formal; e programas de transferência de renda, como o Bolsa Família, que podem provocar efeito de fixar os indivíduos em sua comunidade, tendo em vista que a baixa renda no estado de origem constitui um dos fatores que impactam na probabilidade de migrar.

Portanto, este estudo conclui que o maior nível educacional, dado outras características, possui forte impacto em determinar as migraçóes brasileiras. Ou seja, as pessoas que migram no país entre as unidades da federação são aquelas que possuem níveis de escolaridade mais alto do que os demais, dado que, em geral, são os que possuem menores custos por aquele movimento. Assim, seria interessante para os governantes dos estados a implementação de políticas que atraíssem mais essas pessoas, visto que as mesmas deixam seus lugares de origem em busca de melhores oportunidades e de locais mais desenvolvidos. Logo, aquelas unidades da federação com melhor poder atrativo tendem a ter uma concentração de migrantes com alto nível educacional. Importantes discussôes podem surgir destes resultados para futuros trabalhos, como questôes de desigualdades socioeconômicas que são geradas pela perda da mão-de-obra qualificada de uma regiáo com baixas oportunidades de mercado de trabalho. Visto que, as regióes de destino tendem a ganhar com esses movimentos, enquanto as menos favorecidas tendem a sofrer um retrocesso neste contexto.

\section{Referências}

Basker, Emek (2002), "Education, job search and migration", working paper núm. 02-16, University of Missouri, Columbia, Estados Unidos da América.

Becker, Gary Stanley (1993), Human Capital: a theoretical and empirical approach with special references to education, NBER-University of Chicago, Chicago, Estados Unidos da América.

Borjas, George Jesus (1987), "Immigrants, minorities, and labor market competition”, Industrial \& Labor Relations Review, 40 (3), NBER, Nova Iorque, Estados Unidos da América, pp. 382-392.

Borjas, George Jesus (2008), Issues in the economics of immigration, University of Chicago Press, Chicago, Estados Unidos de América. 
Bound, John, Harry Holzer (2000), "Demand shifts, population adjustments, and labor market outcomes during the 1980s", Journal of Labor Economics, 18 (1), The University of Chicago Press Journals, Chicago, Estados Unidos da América, pp. 20-54.

Braga, Ana Cristina da Silva (2000), "Curvas ROC: aspectos funcionais e aplicaçóes”, tese de doutorado, Universidade do Minho, Braga, Portugal.

Brito, Fausto, Ricardo Alexandrino Garcia e Renata Vieira de Souza (2004), "As tendências recentes das migraçóes interestaduais e o padrão migratório", Encontro Nacional de Estudos de População, v. 14, 20 a 24-setembro, Caxambú-MG, Brasil.

Cameron, Adrian Colin e Pravin Trivedi (2010), Microeconometrics Using Stata, Stata Press, Texas, Estados Unidos da América.

Carvalho, Hugo Emanuel Fávaro de (2010), "Migração, uma análise probit para o Brasil", Dissertação submetida à Universidade Católica de Brasília, Brasília, Brasil.

Cepal (Comissão Econômica para América Latina e o Caribe) (2007), "Panorama social de América Latina", CEPAL, Santiago, Chile.

Cirino, Jader Fernandes (2008), "Participação feminina e rendimento no mercado de trabalho: análises de decomposição para o Brasil e as regióes metropolitanas de Belo Horizonte e Salvador", tese de doutorado, Economia Aplicada - Universidade Federal de Viçosa, Viçosa, Brasil.

Cunha, José Marcos Pinto da (2005), "Migração e urbanização no Brasil: alguns desafios metodológicos para análise”, São Paulo em perspectiva, 19 (4), Fundação Seade, São Paulo, Brasil, pp. 3-20.

Cunha, José Marcos Pinto da (2010), "A migração no Brasil no começo do século 21: continuidades e novidades trazidas pela PNAD 2004", Parcerias Estratégicas, 11 (22), CGEE, Brasília, Brasil, pp. 381-440.

Fávero, Luiz Paulo, Patrícia Belfiore (2014), Métodos quantitativos com Stata, Elsevier, Rio de Janeiro, Brasil. 
Gama, Luz Carlos Day, Ana Flavia Machado (2014), "Migraçãoe rendimientas no Brasil: análise dos factores associados no período intercensitário 2000-2010", Estudos Avançados, 28 (81), Insituto de Estudos Avançados da Universidade de São Paulo, São Paulo, Brasil, pp. 155-174.

Golgher, André Braz (2012), “The selectivity of migration and poverty traps in rural Brazil", Population Review, 51 (1), Sociological Demography Press, Baltimore, Estados Unidos da América, pp. 9-27.

Golgher, André Braz (2006), Diagnóstico do processo migratório no Brasil 3: tipos de migração, Centro de Desenvolvimento e Planejamento Regional da Faculdade de Ciências Econômicas-Universidade Federal de Minas Gerais, Belo Horizonte, Brasil.

Harris, John e Michael Paul Todaro (1970), "Migration, unemployment and development: a two-sector analysis", The American economic review, 60 (1), American Economic Association, Pittsburgh, Estados Unidos da América, pp. 126-142.

Hoffmann, Rodolfo, Marlon Gomes Ney (2008), "A recente queda da desigualdade de renda no Brasil: análise de dados da PNAD, do Censo Demográfico e das Contas Nacionais”, Econômica, 10 (1), Universidade Federal Fluminense, Rio de Janeiro, Brasil, pp. 7-39.

IBGE (Instituto Brasileiro de Geografia e Estatística) (2011), "Notas metodológicas PNAD 2011”, IBGE, Rio de Janeiro, Brasil.

Justo, Wellington Ribeiro e Raul da Mota Silveira Neto (2006), “Migração inter-regional no Brasil: evidências a partir de um modelo espacial”, Revista Economia, 7 (1), Elsevier, Brasília, Brasil, pp. 163-187.

Justo, Wellington Ribeiro e Raul da Mota Silveira Neto (2009), "Quem são e para onde vão os migrantes no Brasil? O perfil do migrante interno brasileiro", Revista da ABET, 8 (1), Brazilian Journal of Labour Studies, São Paulo, Brasil, pp. 125-144.

Lee, Everett (1966), “A theory of migration”, Demography, 3 (1), Max Planck Institute for Demographic Research, Washington, Estados Unidos da América, pp. 47-57. 
Leslie, Gerald Ronnell e Arthur Howard Richardson (1961), "Life-cycle, career pattern, and the decision to move", American Sociological Review, 26 (6), Sage Journals, Chicago, Estados Unidos da América, pp. 894-902.

Machin, Stephen, Kjell Salvanes e Panu Pelkonen (2012), "Education and mobility", Journal of the European Economic Association, 10 (2), Oxford University Press, Oxford, Reino Unido, pp. 417-450.

Martine, George (1990), "As migraçóes de origem rural no Brasil: uma perspectiva histórica”, in Nadalin, Sergio Odilon, Maria Luiza Marcilio e P. Balhana, História e população: estudos sobre a América Latina, Fundação Seade, São Paulo, Brasil.

Massey, Douglas e Maria Aysa-Lastra (2011), "Social capital and international migration from Latin America", International journal of population research, 11(1), Hindawi Publishing Corporation, Cairo, Egito, pp. 1-18.

Mendes, Marcos (2015), "A despesa federal em educação: 2004-2014", Boletim Legislativo, num. 26, Brasília, Brasil.

Ojima, Ricardo e Wilson Fusco (2015), "Migração no semiárido setentrional: dinâmica recente, retorno e políticas sociais", Blucher Social Sciences Proceedings, 2 (2), Blucher, São Paulo, Brasil, pp. 259-276.

Osório, Rafael Guerreiro (2003), "O sistema classificatório de cor ou raça do IBGE”, texto para discussão, Ipea, Brasília, Brasil.

Oliveira, Kleber Fernandes de, Paulo de Martino Jannuzzi (2005), “Motivos para migração no Brasil e retorno ao Nordeste: padróes etários, por sexo e origem/destino", São Paulo em perspectiva, 19 (4), Fundação Seade, São Paulo, Brasil, pp. 134-143.

Patarra, Neide Lopes (2003) "Movimentos migratórios no Brasil: tempos e espaços", texto para discussão, Escola Nacional de Ciências Estatísticas, Rio de Janeiro, Brasil.

Pessoa, Djalma Galvão Carneiro e Pedro Luis Nascimento Silva (1998), "Análise de dados amostrais complexos", Associação Brasileira de Estatística, 112, ABE, São Paulo, Brasil. 
Pindyck, Robert Stephen e Daniel Rubinfeld (2004), Econometria: modelos e previsóes, Elsevier, Rio de Janeiro, Brasil.

PNDA (Pesquisa Nacional par Amastra de Domicilias) (2014), "Microdatos 2014”, Instituto Brasileiro de Geografia e Estatística, Rio de Janeiro, Brasil.

PNDA (Pesquisa Nacional par Amastra de Domicilias) (2009), "Microdatos 2004”, Instituto Brasileiro de Geografia e Estatística, Rio de Janeiro, Brasil.

PNDA (Pesquisa Nacional par Amastra de Domicilias) (2004), "Microdatos 2009”, Instituto Brasileiro de Geografia e Estatística, Rio de Janeiro, Brasil.

Ravenstein, Ernest George (1885), “The laws of migration”, Journal of the Statistical Society of London, 48 (2), Blackwell Publishing, Londres, Reino Unido, pp. 167-235.

Rigotti, José Irineu Rangel e Idamila Renata Pires Vasconcellos (2005), "Uma análise espacial exploratória dos fluxos populacionais brasileiros nos períodos 1986-1991 e 1995-2000", Anais do IV Encontro Nacional sobre Migraçóes da ABEP, 16 a 18-novembro, Rio de Janeiro, Brasil.

Sabbadini, Ricardo e Carlos Roberto Azzoni (2006), "Migração interestadual de pessoal altamente educado: evidências sobre a fuga de cérebros", Anais do XXXIV Encontro Nacional de Economia, 5 a 8 dezembro, Salvador, Brasil.

Sachsida, Adolfo, Paulo Furtado de Castro, Mario Jorge Cardoso de Mendonça e Pedro Albuquerque (2009), "Perfil do migrante brasileiro", texto para discussão, 1410, Ipea, Rio de Janeiro, Brasil.

Santos Júnior, Enestor da Rosa dos; Naércio Menezes Filho e Pedro Cavalcanti Ferreira (2005), "Migração, seleção e diferenças regionais de renda no Brasil", Pesquisa e Planejamento Econômico, Ipea, Brasília, Brasil.

Sasaki, Elisa Massae e Gláucia de Oliveira Assis (2000), “Teorias das migraçóes internacionais", Anais do XII Encontro Nacional da ABEP, 23 a 27 outubro, Caxambu, Brasil. 
Sjaastad, Larry (1962), "The costs and returns of human migration", Journal of Political Economy, 70 (5), University of Chicago, Chicago, Estados Unidos de América, pp. 80-93.

Sobral, Eryka Fernanda Miranda, Ciro Humberto Santos Aragão e Olga Mariana Salgado Santana (2012), "Movimentos migratórios na América do Sul (décadas de 1990 e 2000): uma análise ao Cone Sul", Anais do XVIII Encontro Nacional de Estudos Populacionais, ABEP, 19 a 23 novembro, Lindóia-Sao Paulo, Brasil.

Stark, Oded e J. Edward Taylor (1989) "Relative deprivation and international migration”, Demography, 26 (1), Max Planck Institute for Demographic Research, Washington, Estados Unidos da América, pp. 1-14.

Weiss, Christoph Tancrède Laurent (2015), "Education and regional mobility in Europe", Economics of Education Review, 49, Elsevier, Chicago, Estados Unidos de América, pp. 129-141.

Wooldridge, Jeffrey Marc (2002), Econometric analysis of cross-section and panel data, The MIT Press, Cambridge-Massachusetts, Estados Unidos da América.

Recibido: 24 de febrero de 2017. Corregido: 3 de julio de 2017. Aceptado: 2 de agosto de 2017.

Fransuellen Paulino-Santos. Mestranda em Economia pela Universidade Federal de Viçosa, possui graduação em Ciências Econômicas pela Universidade Federal de Ouro Preto (2015), Áreas de atuação: Economia Geral. Endereço Profissional: Universidade Federal de Viçosa, Departamento de Economia.

Anna Clara Vieira-Silva. Mestranda em Economia pelo Departamento de Economia da Universidade Federal de Viçosa, graduada em Ciências Econômicas pela Universidade Federal de Minas Gerais (2016), Áreas de atuação: Economia Geral. Endereço Profissional Universidade Federal de Viçosa, Departamento de Economia.

Francisco Carlos da Cunha-Cassuce, Doutorado em Economia Aplicada pela Universidade Federal de Viçosa. Atualmente é professor adjunto 
do Departamento de Economia da Universidade Federal de Viçosa. Coordenador do Curso de Ciências Econômicas. Áreas de atuação: Economia Geral. Publicaçóes: "Avaliação do desempenho escolar dos estudantes da região Nordeste que realizaram o ENEM: uma análise com modelos hierárquicos", Espacios, 38 (5), Sociacion de Profesionales y tecnicos del CONICIT, Caracas, Venezuela p. 12-24 (2017); "Relação entre renda e nível educacional e a experiência dos trabalhadores nos diferentes estratos de rendimentos no Norte do Brasil", Novos Cadernos NAEA, 19 (1), Periódicos UFPA, Pará, Brasil, pp. 215-236, (2016); “O impacto do programa nota fiscal paulista na expansão das receitas tributárias do Estado", Espacios, 36 (17), Sociacion de Profesionales y tecnicos del CONICIT, Caracas, Venezuela, pp. 3-18 (2015).

Jader Fernandes-Cirino. Doutor e Mestre pela Universidade Federal de Viçosa, Professor Adjunto do Departamento de Economia da Universidade Federal de Viçosa, Coordena o Índice de Preços ao Consumidor de Viçosa (IPC-Viçosa) e Membro da Comissão Coordenadora do Mestrado em Economia do Departamento de Economia da Universidade Federal de Viçosa. Áreas de atuaçáo: Mercado de Trabalho, Microeconometria, Economia dos Recursos Naturais, Teoria Microeconômica e Políticas Públicas. Publicaçóes. "Avaliação do desempenho escolar dos estudantes da região Nordeste que realizaram o ENEM: uma análise com modelos hierárquicos", Espacios, 38 (5), Sociacion de Profesionales y tecnicos del CONICIT, Caracas, Venezuela p. 12-24 (2017); "Especialização versus diversificação: economias de aglomeração e seus impactos sobre os salários industriais em Minas Gerais", Gestão \& Regionalidade, núm. 32, Universidade Municipal de São Caetano do Sul, São Paulo, Brasil, pp. 143-159 (2016); "Relação entre renda e nível educacional e a experiência dos trabalhadores nos diferentes estratos de rendimentos no Norte do Brasil", Novos Cadernos NAEA, 19 (1), Pará, Brasil, pp. 215-236 (2016). 